\title{
Perfusion Index is Increased in Acute Complex Regional Pain Syndrome Type 1
}

\author{
Ahmet TUTOĞLU, ${ }^{1}$ Ahmet BOYACI, ${ }^{1}$ Ahmet KÜÇÜK, ${ }^{2}$ Ali ŞAKALAR, ${ }^{1}$ Hüseyin SERT, ${ }^{2}$ Şaban YALÇIN ${ }^{2}$ \\ ${ }^{1}$ Department of Physical Medicine and Rehabilitation, Medical Faculty of Harran University, Şanlurfa, Turkey \\ ${ }^{2}$ Department of Anesthesiology and Reanimation, Medical Faculty of Harran University, Şanluurfa, Turkey
}

\begin{abstract}
Objectives: This study aims to investigate whether perfusion index (PI) changes in the affected extremity of complex regional pain syndrome (CRPS) patients compared to other extremities, and define the possible value of this noninvasive method in evaluating CRPS patients' peripheral perfusion. Patients and methods: Twenty-five CRPS type 1 patients (17 males, 8 females; mean age $37.9 \pm 15.1$ years; range 20 to 53 years) who fulfilled the Budapest criteria and 22 age, sex and body mass index matched healthy controls from the staff of our hospital were enrolled. The patients and controls were laid in supine position with the palms facing upward. A pulse oximeter sensor was first attached to the fourth finger of the hand with CPRS, and then to the fourth finger of the unaffected hand. PI values were recorded at five minutes after the attachment of the probe. The control group underwent the same procedure for both extremities.

Results: The PI values were significantly different between healthy and affected hands of the patients $(p=0.007)$. PI values did not show a significant difference between the left and right hands of the subjects in the control group ( $p>0.05)$.

Conclusion: This study suggests that peripheral PI of the extremities of early stage CRPS type 1 patients may be useful in the diagnosis process.

Keywords: Complex regional pain syndrome; hand; perfusion index; pulse oximetry.
\end{abstract}

Complex regional pain syndrome (CRPS) is characterized by severe pain, allodynia, hyperalgesia, and motor and autonomic signs and symptoms. ${ }^{1}$ CRPS type 1 occurs as a severe complication after limb trauma without evidence of peripheral nerve lesion. CRPS has three stages; acute, dystrophic, and atrophic. In the acute period of the disease, signs and symptoms such as pain, increased skin temperature, edema, and redness are common. ${ }^{2}$ The atrophic stage is characterized by the development of irreversible disabilities resistant to therapy, and thus early diagnosis and treatment are crucial.

The diagnosis of CRPS is based on clinical findings rather than imaging methods and laboratory tests. ${ }^{3}$ An increment in the blood flow is noted in the first phase of three phase bone scintigraphy (TPBS) in the acute stage of CRPS ${ }^{4}$ with high specificity in the diagnosis of CRPS.
The perfusion index $(\mathrm{PI})$ is a numerical value that reflects the relative strengths of different components of the infrared signal returning from the monitoring site showing the ratio of pulsatile blood flow to non-pulsatile or static blood in peripheral tissue. It has been shown to reflect the real-time changes in peripheral blood flow from a pulse oximeter continuously and noninvasively. PI values range from $0.02 \%$ for very weak pulse to $20 \%$ for extremely strong pulse. It is believed to provide useful information to the practicing physician in several clinical settings. There have been no studies focusing on the PI in CRPS patients who have altered peripheral perfusion in the affected extremity. In this study, we investigated whether PI changes in the affected extremity of CRPS patients compared to the other extremities, and defined the possible value of this noninvasive method in evaluating CRPS patients' peripheral perfusion. 


\section{PATIENTS AND METHODS}

Twenty-five CRPS type 1 patients (17 males, 8 females; mean age $37.9 \pm 15.1$ years; range 20 to 53 years) were enrolled between March 2013 and July 2013 from among patients who presented to the Physical Medicine and Rehabilitation Outpatient Clinic at the Harran University School of Medicine. All patients fulfilled the Budapest criteria for CRPS. ${ }^{3}$ Twenty-two age, sex and body mass index (BMI) matched healthy controls were recruited from the staff of the same hospital. The research protocol was approved by the Ethics Committee of the Harran University School of Medicine, and written informed consent was obtained from each subjects. All patients underwent TPBS to confirm the diagnosis of CRPS. Patients who were clinically diagnosed with acute phase of CRPS by TPBS were included.

Patients and controls were laid in the supine position with the palms facing upward. The pulse oximeter sensor (LNCS adult adhesive sensor connected to Masimo SET Radical-7 TM Pulse CO-Oximeter; Masimo Corp, Irvine, CA, USA) was first attached to the fourth finger of the hand with CPRS, and then to the fourth finger of the unaffected hand. PI values were recorded at five minutes after the attachment of the probe. The control group underwent the same procedure for both extremities.

\section{Statistical analysis}

Statistical analyses were carried out using SPSS version 18.0 software program (PASW
Statistics for Windows, SPSS Inc., Chicago, IL, USA), and between group comparisons (affected hand vs. healthy hand, or right hand vs. left hand) were made using paired sample t-tests. All demographic and quantitative data are expressed as the mean \pm standard deviation. Differences with $p$ values of $<0.05$ were considered to be statistically significant, and all results are expressed with a 95\% confidence interval.

\section{RESULTS}

Demographic data of the patients and the control group are presented in Table 1 . There were no differences between the subjects in terms of age, gender, BMI, and marital status (all $\mathrm{p}>0.05$ ). Mean disease duration in the patient group was $4.0 \pm 1.4$ months. Of the affected hands, 16 were the right hand and nine were the left hand. The cause of CRPS was a cut in 10 patients, and a fracture in 15 patients.

Perfusion index values in the patient and control groups are shown in Table 2. PI values were significantly different between healthy and affected hands of the patients $(p=0.006)$. PI values did not show a significant difference between left and right hands of the subjects in the control group ( $p>0.05)$.

\section{DISCUSSION}

We hypothesized that the PI of the affected extremity of CRPS acute type 1 patients would

Table 1. Demographic and clinical data of patients and healthy controls

\begin{tabular}{|c|c|c|c|c|c|}
\hline & \multicolumn{2}{|c|}{ Patients $(n=25)$} & \multicolumn{2}{|c|}{ Controls $(n=22)$} & \multirow[b]{2}{*}{$p$} \\
\hline & $\mathrm{n}$ & Mean \pm SD & $\mathrm{n}$ & Mean \pm SD & \\
\hline Age (years) & & $37.88 \pm 15.07$ & & $38.13 \pm 14.11$ & 0.952 \\
\hline \multicolumn{6}{|l|}{ Gender } \\
\hline Male & 17 & & 15 & & 0.989 \\
\hline Female & 8 & & 7 & & \\
\hline Body mass index $\left(\mathrm{kg} / \mathrm{m}^{2}\right)$ & & $22.44 \pm 2.89$ & & $22.38 \pm 2.57$ & 0.934 \\
\hline \multicolumn{6}{|l|}{ Marital status } \\
\hline Married & 17 & & 14 & & \\
\hline Single & 8 & & 8 & & 0.753 \\
\hline Disease duration (months) & & $4.04 \pm 1.39$ & & & \\
\hline \multicolumn{6}{|l|}{ Affected hand } \\
\hline Right & 16 & & & & \\
\hline Left & 9 & & & & \\
\hline \multicolumn{6}{|c|}{ Cause of complex regional pain syndrome } \\
\hline Cut & 10 & & & & \\
\hline Fracture & 15 & & & & \\
\hline
\end{tabular}


Table 2. Patients' and controls' hand perfusion index

\begin{tabular}{|c|c|c|c|c|c|c|c|c|c|c|}
\hline & \multicolumn{2}{|c|}{$\begin{array}{l}\text { Patients' hand } \\
\text { with CRPS }\end{array}$} & \multicolumn{2}{|c|}{$\begin{array}{c}\text { Patients' healthy } \\
\text { hand }\end{array}$} & \multirow[b]{2}{*}{$p$} & \multicolumn{2}{|c|}{$\begin{array}{c}\text { Controls' right } \\
\text { hand }\end{array}$} & \multicolumn{2}{|c|}{$\begin{array}{l}\text { Controls' left } \\
\text { hand }\end{array}$} & \multirow[b]{2}{*}{$p$} \\
\hline & $\mathrm{n}$ & Mean \pm SD & $\mathrm{n}$ & Mean \pm SD & & $\mathrm{n}$ & Mean \pm SD & $\mathrm{n}$ & Mean \pm SD & \\
\hline Perfusion index & 25 & $2.98 \pm 1.59$ & 25 & $1.83 \pm 1.28$ & 0.007 & 22 & $2.91 \pm 1.13$ & 22 & $2.92 \pm 1.12$ & 0.978 \\
\hline
\end{tabular}

be different compared to other extremities. We have found that (i) the mean PI of the affected side were statistically increased compared to the healthy side, and (ii) there were no statistically significant differences between extremities in healthy volunteers.

The physiopathology of CRPS is not fully understood. However, studies to date have suggested that both peripheral and central mechanisms might play a role. ${ }^{5}$ In the acute stage of the disease, functional inhibition of sympathetic vasoconstrictor neurons and consecutive vasodilatation may occur due to autonomic dysfunction. In our study, PI values of healthy hands of CRPS patients' were decreased compared to affected hands of patients. One of the possible explanations might be based on the difference of norepinephrine (NE) levels between affected and healthy sides. Wasner et al. ${ }^{6}$ showed that venous $\mathrm{NE}$ levels were statistically decreased in affected side indicating a substantial decrease of transmitter release from postganglionic sympathetic vasoconstrictor fibers. In a similar study, Harden et al. ${ }^{7}$ demonstrated that subjects with CRPS have asymmetric venous pool plasma concentrations of NE when affected and unaffected limbs are compared, decreased $\mathrm{NE}$ levels in the affected limb. Although we did not measure NE levels in the current study, we think that the possible NE difference between extremities might cause this decreased value of PI in healthy extremities of CRPS patients. Furthermore, in technical perspective, our hypothesis was based on evaluation of PI in the same patient at the same time. We believe that differences between extremities are clinically significant in same patients, and comparing the values of healthy controls and CRPS patients might have limitations with many factors affecting measured values including environmental factors, conditions related to chronic health status, smoking, position or sympathetic/ parasympathetic balance. Accordingly, in clinical evaluation, healthy extremities of CRPS patients might be accepted as control values of the same patient. Studies focusing on significant difference percentages may contribute to the clinical value of this noninvasive method.

The diagnosis of CRPS is essentially based on clinical signs and symptoms. ${ }^{2,8}$ No specific diagnostic test for CRPS exists, although several methods may be useful to support the clinical judgment. ${ }^{9,10}$ Technetium-99m-labelled TPBS is a valuable tool for evaluating metabolic changes in bone tissue, and studies have also reported high sensitivity (60-80\%) and specificity (75-80\%) in diagnosing CRPS. ${ }^{4,11}$ However, scintigraphy has been noted to have a negative effect on the fetus in all three trimesters. ${ }^{12}$ Thus use of this technique is restricted in pregnant women or suspicions of pregnancy. In addition, the need for a fixed gamma camera is another restriction of this method.

The PI is an indirect, noninvasive, and continuous measure of peripheral perfusion that provides useful information to the practicing physician in several clinical settings, including general and regional anesthesia, and also in the neonatal acute care setting. Novel studies focusing on the role of PI in regional anesthesia settings concluded that PI monitoring may provide a highly valuable tool to quickly evaluate the success of regional anesthesia of the upper extremity in clinical practice. ${ }^{13,14} \mathrm{PI}$ was also reported to be an earlier, clearer and more sensitive indicator of the development of epidural-induced sympathectomy. ${ }^{15}$ In spinal anesthesia, PI has been associated with profound hypotension and it has been shown that baseline PI could predict the incidence of spinal anesthesia-induced hypotension during caesarean delivery. ${ }^{16}$ Also, in elective cesarean section a decreased PI value was found to be a maternal predictor of increased neonatal 
morbidity and was significantly related to subclinical placental inflammatory disease. ${ }^{17}$

In the upper extremities of the patients with hyperhydrosis, the intraoperative PI was shown to be an indicator of successful thoracic sympathectomy. ${ }^{18}$ Also in propofol-anesthetized adult patients, the PI was found to be a reliable alternative to conventional hemodynamic criteria for detection of an intravascular injection of epidural test dose. ${ }^{19}$ Furthermore, PI was shown to be a reliable and simple alternative to conventional hemodynamic criteria for detection of stress response to insertion of i-gel, laryngeal mask airway and endotracheal tube in adult patients. ${ }^{20}$

In the neonatal acute care setting, a low PI has been shown to be an objective and accurate measure of acute illness. Additionally, PI measurement represents a more rapid and inexpensive method to assess peripheral perfusion and circulatory status in comparison to evaluating calf muscle perfusion and oxygen consumption by way of near-infrared spectroscopy. ${ }^{21}$ Similar to the aforementioned studies, the current data showed that the PI of affected extremities of CRPS patients significantly increased compared to the unaffected extremity of the same patient. This might be due to pathophysiological processes in CRPS patients causing increased peripheral perfusion of affected extremities.

Several limitations of the present study should be noted. The potential limitations are the absence of long-term clinical follow-up of the CRPS patients and a relatively small sample size. We did not study reproducibility of data with this method in the same patients after a time interval. We think that further studies focusing on reproducibility of this method might be valuable. It should also be noted that generalizing data of the present study might not be appropriate because the results were derived from a population from the same geographic region and genetic origin. Subjects from other geographic region(s) and genetic origin(s) might have different results than our study population.

This study has highlighted that PI might be an alternative, indirect, noninvasive (without radioactivity), user friendly, and continuous measure of peripheral perfusion of the extremities of early stage CRPS type 1 patients that may be useful in the diagnosis process or in evaluating the response to treatment. Further large scale studies focusing on precise diagnostic values and investigating the role in evaluation of treatment should be carried out.

\section{Declaration of conflicting interests}

The authors declared no conflicts of interest with respect to the authorship and/or publication of this article.

\section{Funding}

The authors received no financial support for the research and/or authorship of this article.

\section{REFERENCES}

1. Marinus J, Moseley GL, Birklein F, Baron R, Maihöfner C, Kingery WS, et al. Clinical features and pathophysiology of complex regional pain syndrome. Lancet Neurol 2011;10:637-48.

2. Harden RN, Bruehl S, Perez RS, Birklein F, Marinus J, Maihofner $C$, et al. Validation of proposed diagnostic criteria (the "Budapest Criteria") for Complex Regional Pain Syndrome. Pain 2010;150:268-74.

3. Harden RN, Bruehl S, Stanton-Hicks M, Wilson PR. Proposed new diagnostic criteria for complex regional pain syndrome. Pain Med 2007;8:326-31.

4. Wüppenhorst N, Maier C, Frettlöh J, Pennekamp W, Nicolas V. Sensitivity and specificity of 3-phase bone scintigraphy in the diagnosis of complex regional pain syndrome of the upper extremity. Clin J Pain 2010;26:182-9.

5. Maihöfner C, Seifert F, Markovic K. Complex regional pain syndromes: new pathophysiological concepts and therapies. Eur J Neurol 2010;17:649-60.

6. Wasner G, Heckmann K, Maier C, Baron R. Vascular abnormalities in acute reflex sympathetic dystrophy (CRPS I): complete inhibition of sympathetic nerve activity with recovery. Arch Neurol 1999;56:613-20.

7. Harden RN, Duc TA, Williams TR, Coley D, Cate JC, Gracely RH. Norepinephrine and epinephrine levels in affected versus unaffected limbs in sympathetically maintained pain. Clin J Pain 1994;10:324-30.

8. Li Z, Smith BP, Smith TL, Koman LA. Diagnosis and management of complex regional pain syndrome complicating upper extremity recovery. $\mathrm{J}$ Hand Ther 2005;18:270-6.

9. Birklein F. Complex regional pain syndrome. J Neurol 2005;252:131-8.

10. Vacariu G. Complex regional pain syndrome. Disabil Rehabil 2002;24:435-42.

11. Zyluk A. The usefulness of quantitative evaluation of three-phase scintigraphy in the diagnosis of posttraumatic reflex sympathetic dystrophy. J Hand Surg Br 1999;24:16-21. 
12. Bural GG, Laymon CM, Mountz JM. Nuclear imaging of a pregnant patient: should we perform nuclear medicine procedures during pregnancy? Mol Imaging Radionucl Ther 2012;21:1-5.

13. Kus A, Gurkan Y, Gormus SK, Solak M, Toker K. Usefulness of perfusion index to detect the effect of brachial plexus block. J Clin Monit Comput 2013;27:325-8.

14. Sebastiani A, Philippi L, Boehme S, Closhen D, Schmidtmann I, Scherhag A, et al. Perfusion index and plethysmographic variability index in patients with interscalene nerve catheters. Can J Anaesth 2012;59:1095-101.

15. Ginosar Y, Weiniger CF, Meroz Y, Kurz V, Bdolah-Abram T, Babchenko A, et al. Pulse oximeter perfusion index as an early indicator of sympathectomy after epidural anesthesia. Acta Anaesthesiol Scand 2009;53:1018-26.

16. Toyama S, Kakumoto M, Morioka M, Matsuoka K, Omatsu H, Tagaito Y, et al. Perfusion index derived from a pulse oximeter can predict the incidence of hypotension during spinal anaesthesia for Caesarean delivery. Br J Anaesth 2013;111:235-41.

17. De Felice C, Leoni L, Tommasini E, Tonni G, Toti P,
Del Vecchio A, et al. Maternal pulse oximetry perfusion index as a predictor of early adverse respiratory neonatal outcome after elective cesarean delivery. Pediatr Crit Care Med 2008;9:203-8.

18. Klodell CT, Lobato EB, Willert JL, Gravenstein N. Oximetry-derived perfusion index for intraoperative identification of successful thoracic sympathectomy. Ann Thorac Surg 2005;80:467-70.

19. Mowafi HA, Ismail SA, Shafi MA, Al-Ghamdi AA. The efficacy of perfusion index as an indicator for intravascular injection of epinephrine-containing epidural test dose in propofol-anesthetized adults. Anesth Analg 2009;108:549-53.

20. Atef HM, Fattah SA, Gaffer ME, Al Rahman AA. Perfusion index versus non-invasive hemodynamic parameters during insertion of i-gel, classic laryngeal mask airway and endotracheal tube. Indian $\mathrm{J}$ Anaesth 2013;57:156-62.

21. Zaramella P, Freato F, Quaresima V, Ferrari M, Vianello A, Giongo D, et al. Foot pulse oximeter perfusion index correlates with calf muscle perfusion measured by near-infrared spectroscopy in healthy neonates. J Perinatol 2005;25:417-22. 